\title{
Ontogeny of Unconjugated Estriol in Fetal Blood and the Relation of Estriol Levels at Birth to the Development of Respiratory Distress Syndrome
}

\author{
C. RICHARD PARKER, JR., GARY D. V. HANKINS, DAVID S. GUZICK, \\ CHARLES R. ROSENFELD, AND PAUL C. MACDONALD
}

\begin{abstract}
Department of Obstetrics and Gynecology, The University of Alabama at Birmingham, Birmingham, Alabama 35294 [C.R.P.] and Cecil H. and Ida Green Center for Reproductive Biology Sciences and the Departments of Obstetrics and Gynecology, Biochemistry and Pediatrics, The University of Texas Southwestern Medical School,
\end{abstract} Dallas, Texas

\begin{abstract}
Unconjugated estriol (E3) was quantified in serum of umbilical cord blood of 533 newborn infants, 360 of whom were delivered between 23 and 37 wk of gestation. Serum $E 3$ levels rose $(F=7.71, p<0.0001)$ as a function of gestational age; the mean concentration of $\mathrm{E} 3$ at 37.5 42 wk of gestation $(105 \mathrm{ng} / \mathrm{ml}, n=173)$ was significantly higher than that in serum of newborns delivered at 23-28 wk of gestation $(63 \mathrm{ng} / \mathrm{ml}, n=33)$. Umbilical cord serum levels of $\mathrm{E} 3$ were significantly higher among newborns delivered vaginally between 31.5 and 42 wk of gestation than among newborns delivered by cesarean section $(p<$ 0.005). Although serum E3 levels correlated highly ( $p<$ 0.0001) to newborn weight throughout the entire period of gestation, there was no relationship of newborn weight to umbilical serum E3 levels within a given gestational period. Also, the umbilical serum levels of E3 in male infants were similar to those of female infants at each gestational age. Significant changes in umbilical serum levels of $\mathbf{E 3}$ as a function of gestational age were not observed among newborns $(n=90)$ who developed respiratory distress syndrome (RDS). The mean umbilical serum concentration of $\mathrm{E} 3$ in newborns delivered at 34.5-37 wk of gestation who developed RDS were significantly lower $(p<0.01)$ than that in similar aged newborns whose lung function was normal. Based on the results of multiple logistic regression analyses, we estimated that for each week between 28.536 wk of gestation, the probability of RDS in infants in whom the E3 level was at the 10th percentile was about $7 \%$ greater than that in newborns in whom the $\mathrm{E} 3$ level was at the 50th percentile; the probability of RDS in infants with an E3 level at the 90th percentile was about $10 \%$ lower than that in newborns in whom the E3 level was at the 50th percentile. These data are suggestive that with normal intrauterine development, fetal tissues are exposed to unconjugated E3 in progressively increasing concentrations during the latter half of gestation. When fetal levels of E3 do not increase during this critical period of development, there is an increased risk of development of RDS. (Pediatr Res 21: 386-390, 1987)
\end{abstract}

\section{Abbreviations}

RDS, respiratory distress syndrome E1, estrone

Received September 8, 1986; accepted November 25, 1986

Address all correspondence to C. Richard Parker, Jr., Department of Obstetrics and Gynecology, University of Alabama at Birmingham, University Station, Birmingham, AL 35294.

Supported, in part, by NIH Grants HD14513/22969 and HD13912.

\author{
E2, estradiol \\ E3, estriol \\ CS, cesarean section \\ DS, dehydroepiandrosterone sulfate
}

Estrogens serve an important role in pregnancy, presumably by virtue of the effects of these agents in the pregnant woman and by way of actions in the fetus. Whereas changes in the concentrations of estrogens in blood and urine of women during normal as well as complicated pregnancy are well defined, there are relatively few reports of studies of estrogens in the fetus and newborn (1-10). Estrogens are believed to be important in fetal lung development, especially the maturation of processes that lead to increased capacity for surfactant production (11-13); this presumed action of estrogen may result from direct effects on the lungs, or by way of augmenting pituitary secretion of prolactin (14), which has been suggested by some to be a stimulant of lung surfactant synthesis (15-19), or both. Indeed, the findings of some investigators are suggestive that reduced estrogen levels in blood or urine of newborns are associated with newborn respiratory difficulties $(1,2,4,7)$. For these reasons, we sought to define during the latter half of gestation the ontogeny of estriol, the most abundant unconjugated estrogen in fetal serum and to ascertain whether delayed lung maturation, as indicated by the development of RDS, in newborn infants was associated with low levels of E3 in umbilical cord blood at birth.

\section{METHODS}

The subjects of this prospective study were 533 newborn infants, 360 of who were delivered at or before $37 \mathrm{wk}$ of gestation. This population is not a representative cross-section of newborns, but rather was assembled based on our interests in the ontogeny of the feto-placental unit during normal as well as complicated gestation. Gestational age was computed as the number of weeks since the commencement of the last menstrual period and was defined as the best obstetrical estimate according to the date of the last menstrual period, serial uterine size estimates, onset of fetal heart tones, and sonographic estimates if available. When obstetrical data were inconclusive, gestational age was estimated from the pediatric examination. After delivery, blood (mixed venous and arterial) was drained from a segment of the umbilical cord. After clot formation, serum was separated by centrifugation and stored frozen at $-20^{\circ} \mathrm{C}$. Unconjugated estriol, which was extracted from serum $(50 \mu \mathrm{l})$ with diethyl ether $(2 \mathrm{ml})$, was measured without further purification by radioimmunoassay 
using a highly specific antiserum (20). The within- and betweenassay coefficients of variation for this assay were 7 and $12 \%$, respectively. Estriol values were adjusted for procedural losses during extraction by monitoring the recovery of trace amounts $(500 \mathrm{cpm})$ of ${ }^{3} \mathrm{H}-\mathrm{E} 3$ that had been added to each serum sample prior to extraction. The data for serum E3 concentrations were coded in a VAX 11/780 computer data base along with other newborn data including gestational age, method of delivery (vaginal or cesarean section), sex, and the status of lung function of the neonates. Data relating to the above variables, other than E3 and gestational age, were not obtained for some of the subjects: newborn sex $-52(9.7 \%)$, delivery method $-2(0.4 \%)$, and newborn lung function $-47(8.8 \%)$. When appropriate, serum E3 levels for such subjects were not included in statistical analyses.

The diagnosis of RDS was established in 90 newborn infants by neonatologists who had no knowledge of the hormonal data. The criteria used for establishing the diagnosis of RDS included the presence of grunting respirations and retractions, an increased oxygen requirement $\left(\mathrm{FiO}_{2}>0.4\right)$, a chest radiograph and laboratory findings consistent with a diagnosis of RDS and the exclusion of other causes of respiratory distress. Of the newborns with RDS, $42 \%$ were female and $58 \%$ were males. Whereas there was no significant relation of newborn sex to lung function for the entire population, at 31.5-34 wk of gestation there was a significant relationship between these variables: males- $42 \%$ RDS, $58 \%$ normal; females-20\% RDS, $80 \%$ normal; $p=0.03$. Within each gestational period, the weights of newborns who developed RDS were not different from those of newborns having normal lung function in the neonatal period. Data for 42 newborns in whom respiratory problems other than RDS were believed to exist, e.g. transient tachypnea, pneumonia, etc., were excluded from analyses in which newborns having normal lung function were compared with those having RDS, as were data for 47 newborns whose pulmonary function could not be ascertained readily. Completely normal lung function occurred in 354 newborns, $51 \%$ of whom were females and $48 \%$ of whom were males. Of the women who delivered infants without obvious respiratory disease, $45 \%$ had uncomplicated pregnancies, $25 \%$ had pregnancy-induced hypertension, $6 \%$ had chronic hypertension, $7 \%$ had diabetes, $21 \%$ had multiple gestations, and $6 \%$ had other complications of pregnancy. Of the women who delivered infants who developed RDS, 58\% had uncomplicated pregnancies, $12 \%$ had pregnancy-induced hypertension, $2 \%$ had chronic hypertension, $7 \%$ had diabetes, $19 \%$ had multiple gestations,

Table 1. Umbilical cord serum concentrations of unconjugated E3: Relation to gestational age*

\begin{tabular}{llcccc}
\hline & \multicolumn{5}{c}{ Wk of gestation } \\
\cline { 2 - 6 } & $23-28$ & $28.5-31$ & $31.5-34$ & $34.5-37$ & $37.5-42$ \\
\hline Mean & $62.9^{a}$ & $72.9^{a}$ & $75.2^{a}$ & $84.2^{a}$ & $105.4^{b}$ \\
SD & 39.4 & 44.2 & 47.9 & 58.8 & 68.0 \\
$n$ & 33 & 41 & 118 & 168 & 173 \\
\hline
\end{tabular}

* Serum E3 levels in $\mathrm{ng} / \mathrm{ml}$; to convert to $\mathrm{nmol} / \mathrm{l}$, multiply by 3.472 . Values having different superscripts are significantly different $(p<0.05)$, using the Newman-Keuls multiple range test. and $8 \%$ had other pregnancy complications. None of the pregnant women had been administered glucocorticosteroids in an attempt to facilitate fetal lung maturation. The conduct of these studies was approved by the Institutional Review Boards of the University of Texas Health Science Center at Dallas and the University of Alabama at Birmingham. The data were subjected to analysis of variance, Newman-Keuls multiple range test, unpaired $t$ test, multiple logistic regression analysis, $\chi^{2}$ test, and linear regression analysis using SAS (21) in a VAX 11/780 computer.

\section{RESULTS}

Ontogeny of umbilical cord serum E3. The concentrations of E3 in serum of umbilical cord blood of the entire population of newborns $(n=533)$ of this study are grouped according to gestational age in Table 1. Whereas the minimum level of $\mathrm{E} 3$ in serum did not change appreciably during the gestational period of study, the maximum concentration of E3 rose progressively as a function of gestational age. A stepwise, direct relationship between $\mathrm{E} 3$ and gestational age was found $(\mathrm{F}=7.71, p<0.0001)$. At term, umbilical cord blood serum E3 levels were significantly higher than those in infants born at 23-37 wk of gestation.

Relation of umbilical cord serum E3 to newborn weight, sex, and route of delivery. A highly significant relation between umbilical serum levels of E3 and newborn weight was observed throughout gestation $(\mathrm{F}=19.94, p<0.0001)$. Within each gestational age group (i.e. those in Table 1), however, there was no significant correlation between serum E3 levels and newborn weights. Umbilical cord serum levels of E3 were slightly, although not significantly, greater in female newborns than in male newborns of a similar gestational age (Table 2). An effect of delivery method on umbilical cord serum levels of E3 was observed; after 31 wk of gestation, the serum levels of E3 among newborns delivered by cesarean section were significantly lower than those among newborns delivered vaginally (Fig. 1).

In this prospective study, we did not always ascertain whether cesarean section occurred in the presence or absence of labor. In those instances, however, when such information was obtained, serum E3 levels tended to be higher $(p>0.05)$ in newborns delivered by CS after the commencement of labor than in its absence. For example, at 34.5-37 wk, CS + labor $=67.1 \pm 8.9$ $\mathrm{ng} / \mathrm{ml}(n=10)$ and CS no labor $=51.6 \pm 10.9 \mathrm{ng} / \mathrm{ml}(n=13)$; at $37.5-42 \mathrm{wk}, \mathrm{CS}+$ labor $=76.0 \pm 8.4 \mathrm{ng} / \mathrm{ml}(n=17)$ and $\mathrm{CS}$ no labor $=66.9 \pm 6.1 \mathrm{ng} / \mathrm{ml}(n=29)$. It should be noted, however, that serum E3 levels at both age groups were lower $(p$ $<0.05$ ) in newborns delivered by CS after the onset of labor than in those delivered vaginally.

Relation of umbilical cord serum E3 to newborn lung function. The concentrations of E3 in umbilical cord serum of newborns who developed RDS are compared with those from newborns who experienced no respiratory problems in Figure 2. Whereas a progressive increase in serum E3 concentrations as a function of gestational age was observed in newborns in whom lung function was normal, there was no significant variation in serum E3 concentrations as a function of gestational age among newborns who developed RDS $(F=0.26, p=0.90)$. At each gestational period, the mean umbilical cord serum concentration of E3 was lower in newborns who developed RDS than that in

Table 2. Lack of effect of fetal sex on umbilical cord serum E3 concentration

\begin{tabular}{cccccc}
\hline & \multicolumn{5}{c}{ Wk of gestation } \\
\cline { 2 - 5 } Serum E ${ }_{3}^{*}$ & $23-28$ & $28.5-31$ & $31.5-34$ & $34.5-37$ & $37.5-42$ \\
\hline Males & $58.8 \pm 8.8$ & $64.0 \pm 8.9$ & $77.9 \pm 6.7$ & $83.2 \pm 6.8$ & $103.0 \pm 7.3$ \\
$n$ & 15 & 17 & 51 & 85 & 91 \\
Females & $67.4 \pm 14.0$ & $79.9 \pm 11.2$ & $79.7 \pm 7.3$ & $85.9 \pm 7.2$ & $109.2 \pm 7.6$ \\
$n$ & 11 & 20 & 46 & 66 & 79 \\
\hline
\end{tabular}

${ }^{*}$ Umbilical serum $\mathrm{E} 3$ levels are expressed in $\mathrm{ng} / \mathrm{ml}$ and are presented as the mean \pm SE. $P>0.05$ at each gestational age. 


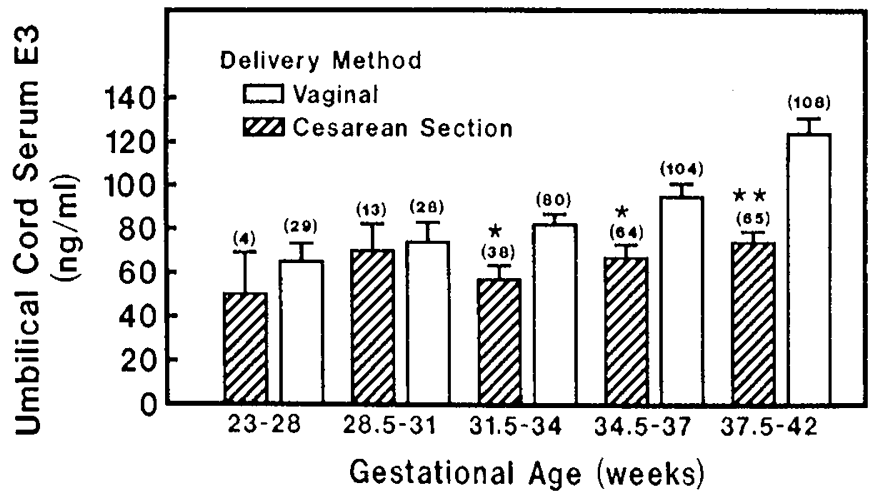

Fig. 1. Effect of method of delivery on the concentrations of E3 in mixed umbilical cord serum. The data are subdivided according to gestational age and are presented as the mean \pm SE. ${ }^{*} p<0.05,{ }^{* *} p<$ 0.01 compared to values in newborns delivered vaginally.

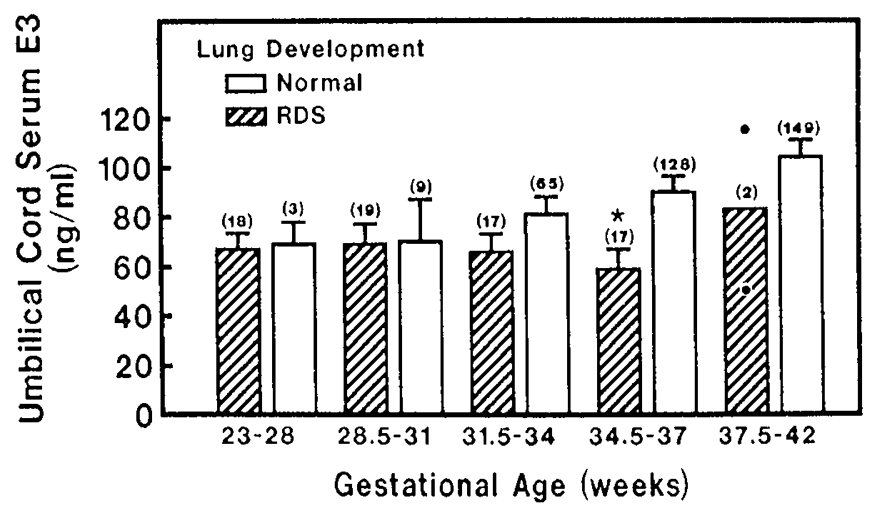

Fig. 2. Relationship between umbilical cord serum E3 and newborn pulmonary function. The data are subdivided according to gestational age and are presented as the mean $\pm \mathrm{SE} .{ }^{*} p<0.05$ compared to value for newborns having normal respiratory function.

newborns in whom respiratory function remained normal; these differences in serum E3 levels were statistically significant at $34.5-37$ wk of gestation $(p<0.01)$. On the other hand, umbilical serum levels of E3 in newborns who developed respiratory problems other than RDS were not significantly different from those in newborns having normal lung function. For example, E3 levels in such newborns having other respiratory problems at $30.5-34 \mathrm{wk}(74.1 \pm 14.7 \mathrm{ng} / \mathrm{ml}, n=14)$ and at $37.5-42 \mathrm{wk}(115$ $\pm 40.6 \mathrm{ng} / \mathrm{ml}, n=4)$ were similar to those in age-matched newborns having normal lung function $(81.4 \pm 6.3$ and $104 \pm$ $5.7 \mathrm{ng} / \mathrm{ml}$, respectively).

The differences in umbilical cord serum levels of $\mathrm{E} 3$ between the group of infants who developed RDS and the group in whom lung function remained normal did not appear to be attributed to differences in delivery method; of those newborns delivered at or before 37 wk of gestation, $34.1 \%$ who developed RDS and $30.9 \%$ in whom lung function was normal were delivered by CS $(p>0.05)$. In both groups of preterm newborns, umbilical cord serum levels of E3 in infants delivered vaginally (normal; $95.0 \pm$ $5.2 \mathrm{ng} / \mathrm{ml}$, RDS; $72.0 \pm 5.5 \mathrm{ng} / \mathrm{ml})$ were higher $(p<0.005$ and $\mathrm{p}<0.05$, respectively) than those in newborns delivered by CS (normal; $70.0 \pm 6.4 \mathrm{ng} / \mathrm{ml}, \mathrm{RDS} ; 53.1 \pm 5.8 \mathrm{ng} / \mathrm{ml}$ ). Also, whereas the proportion of male infants developing RDS at 31.5$34 \mathrm{wk}$ of gestation $(42 \%)$ exceeded that of females $(20 \%, p=$ 0.03 ), there were no significant sex differences at this age in umbilical serum E3 concentrations among newborns having RDS (males-66.7 $\pm 10.8 \mathrm{ng} / \mathrm{ml}$; females-62.5 $\pm 9.5 \mathrm{ng} / \mathrm{ml}$ ) or those having normal lung function (males-83.5 $\pm 9.9 \mathrm{ng}$ / $\mathrm{ml}$; females-90.0 $\pm 10.0 \mathrm{ng} / \mathrm{ml}$ ).
The relationship between umbilical cord serum E3 and gestational age for the entire population of newborns, for newborns whose lung function was normal, and for newborns who developed RDS was estimated from linear regression analysis (Table 3 ). As illustrated in Table 1, the variance of serum E3 levels increased as a function of gestational age. To obtain unbiased regression estimates, weighted regression analyses were performed by use of the reciprocals of gestational ages as the weights (21). As indicated in Table 3 , there was a statistically significant and positive relationship between gestational age and serum levels of E3 for the values of the entire population of newborns. This was attributable to the relationship found in neonates in whom lung function remained normal; in infants who developed RDS, there was no significant relationship between gestational age and umbilical cord serum levels of E3.

To evaluate further the relationship among umbilical cord serum concentrations of E3, gestational age, and the development of RDS, we subjected the data to multiple logistic regression analysis. A significant, independent, inverse relation of gestational age to the development of RDS was, as expected, observed $(p<0.0001)$. Controlling for the effect of gestational age, a significant inverse relationship between serum E3 and the incidence of RDS also was found $(p=0.017)$. By use of the results of this analysis, we computed the probability of the development of RDS as a function of umbilical cord serum concentration of E3 (Fig. 3). As shown, the estimated probability of developing RDS for newborns with an E3 level that was equal to the 10th

Table 3. Weighted least squares regression analysis of umbilical cord serum $E 3$ as function of gestational age*

\begin{tabular}{lccc} 
& $\begin{array}{c}\text { Total } \\
\text { population }\end{array}$ & $\begin{array}{c}\text { Normal } \\
\text { lung function }\end{array}$ & RDS \\
\hline Intercept & -41.1 & -49.4 & 60.8 \\
& $(22.1)$ & $(43.7)$ & $(40.4)$ \\
Slope & $3.63 \dagger$ & $3.92 \ddagger$ & 0.16 \\
& $(0.63)$ & $(1.19)$ & $(1.16)$ \\
Correlation coefficient & $0.205 \dagger$ & $0.120 \S$ & -0.002 \\
$n$ & 533 & 354 & 90 \\
\hline
\end{tabular}

* The SE of the estimated regression coefficients are shown in parentheses.

$\dagger p<0.001$.

$\ddagger p<0.01$.

$\S p<0.025$.

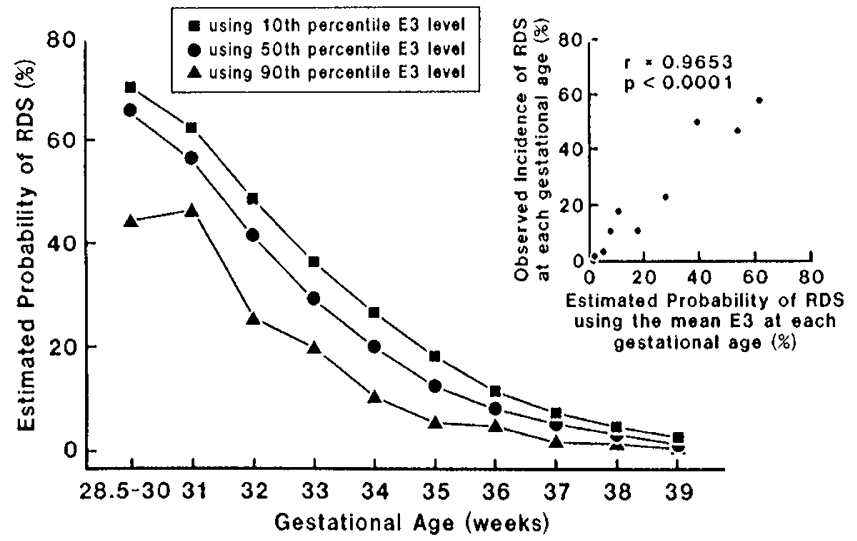

Fig. 3. Relationship between umbilical cord serum levels of E3 and the probability of development of RDS. Probability was estimated using the formula $p$ (Prob. RDS) $=\mathrm{e}^{\mathrm{s}} /\left(1+\mathrm{e}^{\mathrm{s}}\right)$; where $\mathrm{s}=15.864-$ 0.4908 (gestational age) -0.00812 (E3 concentration), as computed by use of multiple logistic regression analysis. The inset shows the correlation between observed incidence of RDS and the incidence that is predicted using the mean serum E3 level between 28.5 and 39 wk of gestation. 
percentile value of the population at each gestational week was increased whereas the probability of developing RDS in newborns with an E3 that was equal to the 90th percentile was decreased, as compared with that in newborns with a value equal to the median (50th percentile) serum E3 level. The validity of these estimates was verified by comparing the observed incidence of RDS with that estimated at the mean serum E3 for each gestational week (inset, Fig. 3); the product-moment correlation between observed and predicted incidence of RDS was highly significant $(p<0.0001)$.

\section{DISCUSSION}

In this study, we found that the concentrations of unconjugated E3 in umbilical cord serum of newborns delivered at term were about twice those found in newborns delivered during the early part of the $3 \mathrm{rd}$ trimester. Both the quantitative and qualitative aspects of these data are similar to those found by other investigators (3-9), whose conclusions were based on considerably fewer observations than those of the present report. The greatest increases in the levels of E3 occurred between 31.5 and $40 \mathrm{wk}$ of gestation, a gestational period that is characterized by a rapid increase in fetal adrenal size and the rate of secretion of the placental estrogen precursor, DS (22), and also an acceleration in the rate of increase of maternal blood levels of E3 (23). Whereas it seems clear that fetal blood E3 levels are linked closely with fetal adrenal activity, as evidenced by markedly subnormal levels of E3 in blood of anencephalic fetuses (3) and in fetuses in whom adrenal steroidogenesis is suppressed after treatment with glucocorticosteroids (24), the "trigger" for the final maturation of the fetal adrenal is, as yet, undefined.

Our results also are indicative that delivery method, and most probably the presence or absence of labor, influences the levels of E3 in fetal blood. These findings are supportive of the conclusions of others who found that the levels of E1 $(5,6)$ and E3 $(9)$ in blood are higher in newborns delivered vaginally than in newborns delivered by CS prior to or during the early stages of labor. The mechanism by which the levels of estrogens in umbilical cord serum become elevated in vaginally delivered newborns is not clear. Smith et al. (6) found that umbilical cord serum E1 levels were about three times higher after vaginal delivery than after $\mathrm{CS}$, while $\mathrm{E} 2$ levels were decreased by about $40 \%$ after vaginal delivery. The change in the E1:E2 ratio after vaginal delivery was considered by these investigators, as well as by Patten et al. (5), to indicate a shift in the metabolism of estrogens in the placenta before or during labor. One also can calculate, from their data, that there is an increase in the total amount of E1 and E2 in fetal blood after labor and vaginal delivery (there also is an increase in E3) (9; current study). Thus, in addition to a possible shift in placental metabolism of estrogens, there would appear to be increased delivery of placentally formed estrogens into the fetal compartment during labor and vaginal delivery. We believe that this may occur as a result of periodic decreases in utero-placental blood flow during uterine contractions, thus allowing estrogens in the placenta greater opportunity to diffuse into the fetal circulation, rather than being "washed away" in the uterine venous blood of the mother.

The last $10 \mathrm{wk}$ of human gestation, and in particular the period between $31-37 \mathrm{wk}$, is a critical time in the preparation of the fetus for successful extrauterine life. One of the major developmental milestones that occurs during this time is the functional maturation of the fetal lung, especially the capacity for surfactant biosynthesis and secretion. Among the newborns of this study, approximately $50 \%$ of those delivered between $23-31 \mathrm{wk}$ of gestation developed RDS; and, fewer than one of five newborns delivered at this stage of gestation had normal respiratory function. Among the infants born between 31.5-34 wk of gestation, the incidence of RDS was about $33 \%$ whereas the incidence of normal lung function rose to about $50 \%$; in infants born during the 34.5-37 wk of gestation, the incidence of RDS was about
$10 \%$ and completely normal lung function occurred in more than $75 \%$ of such newborns. Among the newborns in whom lung function remained normal, there was a progressive increase in umbilical cord serum levels of E3; among those who developed RDS, irrespective of gestational age, the levels of E3 tended to remain at values similar to those found at 23-28 wk of gestation.

$\mathrm{CS}$ is a mode of delivery reported to be associated with increased risk for development of RDS (25) and, as we and others have found (9), a decreased umbilical serum concentration of E3. We found, however, by use of multivariate analysis that there was a statistically significant relation, independent of delivery method, between subnormal umbilical serum levels of E3 and the subsequent development of RDS. On the other hand, within a given gestational age group, we found no correlation between newborn weight and the occurrance of RDS and also found no relation between umbilical serum E3 and newborn weight or sex. We did find, at least between $31.5-34 \mathrm{wk}$, a greater increase of RDS among male than female infants; such findings generally are in agreement with those of others who found that prematurely delivered male infants are more prone than females to develop RDS (26). Among such newborns who developed RDS, however, we found umbilical cord serum E3 levels to be equally low in both males and females.

Others also have investigated the possible relationship between fetal blood levels of estrogens and the development of RDS. Our results, in which a significant deficiency in umbilical serum unconjugated $\mathrm{E} 3$ was found in newborns who delivered between 34.5-37 wk and who subsequently developed RDS, are complementary to and extend the observations of Conley et al. (4) (subnormal levels of total E3 in umbilical cord serum), and of Frank et al. (1), and Dickey and Robertson (2) (subnormal urinary E3 levels). On the other hand, a statistically significant association between estrogens in blood and RDS has not been observed by some groups of investigators $(7,8,10)$. We believe that such negative findings are explainable and, moreover, could have been anticipated. In one such study, peripheral venous samples of blood were obtained from newborns during the first $24 \mathrm{~h}$ of life and analyzed for total E3 (8). The control group for this study was composed of severely ill newborns who were cared for in the intensive care nursery; many of these newborns had "benign respiratory distress," not normal lung function. In the other two studies $(7,10)$, umbilical cord serum E2, rather than E3 was quantified. The concentration of E2 in fetal blood does not appear to be a good marker of developmental processes in the fetus since there is little change in fetal blood levels of E2 throughout most of gestation (10), and, fetal blood levels of E2 are influenced only minimally by the extent of estrogen precursor (DS) production in the fetus (3). Although E3 is considered by some to be a less potent estrogen than is E2, when E3 is present in blood for extended periods of time at high concentrations, this steroid is a very potent estrogen (27). Moreover, throughout most, if not all of gestation, fetal serum concentrations of E3 are $10-15$ times greater than those of E2 $(2-7,9,10,24$, and present study).

Our data are supportive of a correlation between subnormal concentrations of E3 in fetal blood and an increased risk for the development of RDS in the latter stages of gestation. Such an association is consistent with the observation that estrogens act to stimulate maturation of the lungs of fetal rabbits (11-13). Among the effects of estrogen are increased rates of production of surfactant lipids and decreased glycogen content of lung tissue. Estrogens also may act indirectly on the lung by way of stimulating the secretion of pituitary prolactin (14), a hormone that has been implicated by several groups of investigators in the regulation of surfactant lipid biosynthesis and lung maturation (15-19). Lastly, we recently found that in pregnancies complicated by fetal anencephaly, in which we also found severely decreased fetal blood levels of E3 [but not of E2, in agreement with the findings of Tulchinsky et al. (3)], the amniotic fluid lecithin/sphingomyelin ratio is extremely low, even at term (28). 
Findings such as these are suggestive that not only are fetal blood levels of E3 correlated with fetal lung maturation, but E3 also may serve a role in the onset of accelerated surfactant production, which normally occurs near term in the human fetus.

Acknowledgments. The authors thank S. C. MacDonald, R.N. and Susan C. Rawlins, R.N. for their assistance as well as Tim Deahl, Sholeh Golkar, and Gwen Chase for technical support.

\section{REFERENCES}

1. Frank DJ, Yazitzis MP, Gebbhard R 1965 Urinary estriol levels and respiratory distress in the premature infant. J Pediatr 67:677-679

2. Dickey RP, Robertson AF 1969 Newborn estrogen excretion. Am J Obste Gynecol 104:551-555

3. Tulchinsky D, Osathanondh R, Belisle S, Ryan KJ 1977 Plasma estrone, estradiol and estriol and their precursors in pregnancies with anencephalic fetuses. J Clin Endocrinol Metab 45:1100-1103

4. Conly PW, Lemaire WJ, Monkus EF, Cleveland WW 1973 Plasma estriol concentration in infants with the respiratory distress syndrome. J Pediatr $83: 851-853$

5. Patten PT, Anderson ABM, Turnbull AC 1973 Human fetal and maternal plasma oestrogens and the onset of labor. J Obstet Gynecol Br Commonw 80:952-956

6. Smith ID, Shutt DA, Shearman RP 1975 Foetal plasma steroid concentrations related to gestational age and method of delivery. J Steroid Biochem 6:657662

7. Sybulski S, Maughan GB 1975 Umbilical cord plasma estradiol levels in relation to complications of pregnancy and newborn and to cortisol levels. Biol Neonate 27:302-307

8. Reynolds JW, Bentley K, Turnipseed MR 1977 Serum total estriol in abnormal newborn infants. J Steroid Biochem 8:853-858

9. Goldkrand JW 1978 Unconjugated estriol and cortisol in maternal and cord serum and amniotic fluid in normal and abnormal pregnancy. Obstet Gynecol 52:264-271

10. Ho Yuen B, Phillips WDP, Cannon W, Sy L, Redford D, Burch P 1982 Prolactin, estradiol, and thyroid hormones in umbilical cord blood of neonates with and without hyaline membrane disease: a study of 405 neonates from midpregnancy to term. Am J Obstet Gynecol 142:698-703

11. Gross I, Wilson CM, Ingleson LD, Brehier A, Rooney SA 1979 The influence of hormones on the biochemical development of fetal rat lung in organ culture I Estrogen. Biochem Biophys Acta 575:375-383

12. Khosla SS, Gobran LI, Rooney SA 1980 Stimulation of phosphatidylcholine synthesis by $17 \beta$-estradiol in fetal rabbit lung. Biochem Biophys Acta 617:282-290

13. Possmayer F, Casola PG, Chan F, MacDonald P, Ormseth MA, Wong T, Harding PGR, Tokmakjian S 1981 Hormonal induction of pulmonary maturation in the rabbit fetus. Effects of maternal treatment with estradiol$17 \beta$ on the endogenous levels of cholinephosphate, CDP-choline and phosphatidylcholine. Biochem Biophys Acta 664:10-21

14. Yen SSC, Ehara Y, Siler TM 1974 Augmentation of prolactin secretion by estrogen in hypogonadal women. J Clin Invest 53:652-655

15. Hamosh M, Hamosh P 1977 The effect of prolactin on the lecithin content of fetal rabbit lung. J Clin Invest 59:1002-1005

16. Hauth JC, Parker CR, MacDonald PC, Porter JC, Johnston JM 1978 A role of fetal prolactin in lung maturation. Obstet Gynecol 51:81-88

17. Gluckman PD, Ballard PL, Kaplan SL, Liggins GC, Grumbach MM 1978 Prolactin in umbilical cord blood and the respiratory distress syndrome. J Pediatr 93:1011-1014

18. Dhanireddy R, Smith YF, Hamosh M, Mullon DK, Scanlon JW, Hamosh P 1983 Respiratory distress syndrome in the newborn: relationship to serum prolactin, thyroxine and sex. Biol Neonate 43:9-15

19. Porreco RP, Merritt TA, Gluck L 1980 Effect of prolactin on phospholipid biosynthesis by alveolar cell carcinoma (A549) in monolayer tissue culture. Am J Obstet Gynecol 136:1071-1074

20. Wright K, Collins DC, Preedy JRK 1973 Comparative specificity of antisera raised against estrone, estradiol- $17 \beta$ and estriol using 6-O-carboxymethyloxine bovine serum albumin derivatives. Steroids 21:755-769

21. SAS Users Guide: Statistics, Version 5. SAS Institute, Inc, Cary, NC, 1985

22. Parker CR Jr, Leveno K, Carr BR, Hauth J, MacDonald PC 1982 Umbilical cord plasma levels of dehydroepiandrosterone sulfate during human gestation. J Clin Endocrinol Metab 54:1216-1220

23. Parker CR Jr, Hlingworth DR, Bissonnette J, Carr BR 1986 Endocrine changes during pregnancy in a patient with homozygous familial hypobetalipoproteinemia. N Engl J Med 314:557-560

24. Simmer HH, Tulchinsky D, Gold EM, Frankland M, Greipel M, Gold AS 1974 On the regulation of estrogen production by cortisol and ACTH in human pregnancy at term. Am J Obstet Gynecol 119:283-296

25. Farrell PM, Avery ME 1975 Hyaline membrane disease. AM Rev Respir Dis 111:657-688

26. Miller HC, Mead J 1968 Birth weight, gestational age and sex as determining factors in the incidence of respiratory distress syndrome of prematurely born infants. J Pediatr 72:628-635

27. Clark JH, Paszko Z, Peck EJ Jr 1977 Nuclear binding and retention of the receptor estrogen complex; relation to the agonistic and antagonistic properties of estriol. Endocrinology 100:91-96

28. Parker CR Jr, Leveno KJ, Milewich L, MacDonald PC 1986 Lecithin/sphingomyelin ratios in amniotic fluid of pregnancies with an anencephalic fetus. Obstet Gynecol 64:546-549 